\title{
Laboratory properties of cold-adapted influenza B live vaccine strains developed in the US and USSR, and their B/Ann Arbor/1/86 cold-adapted reassortant vaccine candidates
}

\author{
G.I. Alexandrova*, H.F. Maassab ${ }^{\dagger}$, A.P. Kendal ${ }^{\ddagger}$, T.E. Medvedeva*, \\ A.Y. Egorov*, A.I. Klimov ${ }^{\S}$ and N.J. Cox ${ }^{\ddagger}$
}

The adaptation of two influenza $B$ strains (B/Leningrad/14/55 and B/Ann Arbor/1/66) to replication at $25^{\circ} \mathrm{C}$ is described. Comparison of the two viruses indicates that both also exhibit temperature sensitive phenotypes, although that of the virus B/Leningrad/14/55 is less pronounced. When inoculated into ferrets both viruses replicate well in the trachea, but only the $B /$ Leningrad/14/55 cold-adapted virus replicates in the lungs. This virus exhibited a moderate level of attenuation in the animals, in contrast to the B/Ann Arbor/1/66 cold-adapted virus, which was fully attenuated. Reassortant viruses deriving the surface antigens of the contemporary wild type virus B/Ann Arbor/1/86 and most or all of their other genes, from one or other cold-adapted parent, were virtually indistinguishable from their respective cold-adapted parents. The B/Leningrad/14/55 reassortant was slightly more attenuated than its cold-adapted parent in ferrets. These studies extend knowledge of the properties of viruses used to prepare experimental live influenza B human vaccines.

Keywords: Infuenza; attenuated vaccine; virus

\section{Introduction}

A recent method for preparation of attenuated vaccine strains of influenza virus is based on the recombination of contemporary wild-type (wt) viruses with a coldadapted (ca) donor strain. Reassortant viruses which inherit the genes coding for haemagglutinin and neuraminidase from the epidemic virus and most of the other genes from the ca donor strain are then selected by antigenic and molecular analysis ${ }^{1-3}$

Most studies to date with reassortant ca influenza viruses have involved type A strains. The progress with the techniques used has prompted us to extend these procedures to type $B$ influenza vaccine. Presently, the following ca type $B$ influenza strains exist: $B /$ Leningrad/ 14/55, B/USSR/69/60, B/Dushanbe/62 and B/USSR/67, developed in the USSR (Ref. 4 and unpublished results), and B/Massachussetts/66, B/Ann Arbor/1/66 and $\mathrm{B} /$ Tecumseh/1/69 developed in the $\mathrm{US}^{5}$. Although

* Institute of Experimental Medicine, Academy of Medical Sciences of the USSR, Leningrad, 197022, USSR. 'Department of Epidemiology, School of Public Health, University of Michigan, Ann Arbor, Michigan, USA. 'Influenza Branch, Division of Viral Disease, Center for Infectious Diseases, Centers for Disease Control, Public Health Service, US Department of Health and Human Services, Atlanta, GA, 30333, USA. ${ }^{\S}$ Research Institute for Viral Preparations, Academy of Medical Sciences of the USSR, Moscow, 109088, USSR. Correspondence should be addressed to: Alan P. Kendal. (Received 5 January 1989; revised 18 May 1989; accepted 1 August 1989) these viruses have been available for several years, only recently have reassortants begun to be prepared from them for laboratory and clinical analysis.

In 1985/86 major epidemics of influenza B occurred in some countries, including Eastern Europe and the US, in association with high levels of morbidity in children and adults ${ }^{6,7}$. The epidemic was caused by a new antigenic variant, for which the reference strain $\mathrm{B} / \mathrm{Ann}$ Arbor/1/86 was selected for production of the subsequent inactivated vaccine ${ }^{8}$. This opportunity was taken simultaneously to prepare ca reassortant viruses from candidate ca vaccine strains in the US and USSR, and the same wt reference strain, for comparison of their properties. Such a comparison of laboratory properties is described here, with clinical evaluation of the reassortant derived in the USSR described elsewhere ${ }^{9}$.

\section{Materials and methods}

\section{Viruses}

The wt B/Ann Arbor/1/86 strain was isolated during the $1985 / 86$ epidemic in the US. Virus was isolated in specific pathogen free (SPF) eggs, during a single passage, then plaque-purified twice at a temperature of $37^{\circ} \mathrm{C}$ in primary chick kidney cells (PCKC) prepared from SPF embryos, and finally passaged twice more in SPF eggs to prepare a seed pool used as the starting material for preparation of candidate vaccines. The B/Leningrad/14/55 strain was isolated from an ill child in 1955; it had undergone 20 passages in embryonated eggs at a temperature of $32^{\circ} \mathrm{C}$ before being adapted to grow at the 
normally sub-optimal temperature of $25^{\circ} \mathrm{C}$ by 17 passages in embryonated eggs at $25-26^{\circ} \mathrm{C}^{4,10}$. Derivation of the B/Ann Arbor/1/66 ca virus was by passage in $\mathrm{PCKC}$ at successively lower temperatures. Including initial isolation, the virus had received seven PCK passages before being considered adapted to growth at $25^{\circ} \mathrm{C}^{5}$. This was plaque-purified by seven sequential passages in PCKC from SPF embryos, before preparing an egg pool for use in the studies described.

\section{Preparation of ca reassortant viruses}

For preparation of a reassortant virus with the ca B/Leningrad/14/55 parent, virulent B/Ann Arbor/1/86 virus (at a dose of $6.25 \log _{10} \mathrm{EID}_{50} / 0.2 \mathrm{ml}$ ) was partially inactivated by heating (at $36^{\circ} \mathrm{C}$ for $48 \mathrm{~h}$ ), reducing its infectivity by 3.75 logs. This preparation was mixed with an equal volume of untreated ca B/Leningrad/14/55 virus, containing 6.25 logs of infectivity. Chick embryos were infected with a mixture of the viruses and incubated at $34^{\circ} \mathrm{C}$ for $48 \mathrm{~h}$. The reassortant was selected after two passages in the presence of $16-32$ neutralizing units of antiserum to the $B /$ Leningrad/14/55 virus followed by cloning in embryonated eggs at $34^{\circ} \mathrm{C}$ for $72 \mathrm{~h}$ using limited dilution technique. Clones were then selected with antigenic characteristics of the B/Ann Arbor/1/86 virus, and their genome composition screened as described below. A clone designated LEN-B/14/5/1 was used for subsequent studies, after verification it contained only the HA, NA and NS genes from the wild-type parent.

Derivation of the reassortant of wt B/Ann Arbor/1/86 and ca B/Ann Arbor/1/66 was accomplished by mixed infection of $\mathrm{PCKC}$ at $25^{\circ} \mathrm{C}$, and selection in the presence of immune serum to B/Ann Arbor/1/86, as previously described for influenza $A$ viruses ${ }^{1}$. After two cycles of plaque purification at $25^{\circ} \mathrm{C}$, genome composition of reassortant viruses was determined as described below, and the clone designated AA-CRB117 selected for further studies. This reassortant contained only HA and NA of the wt parent virus.

Effect of temperature on replication. Cold-adaptation and temperature sensitivity were determined by either titration in embryonated eggs or PCKC cultures at $25^{\circ} \mathrm{C}$, $32^{\circ}-34^{\circ} \mathrm{C}$, and $37^{\circ} \mathrm{C}, 38^{\circ} \mathrm{C}$ or $39^{\circ} \mathrm{C}$, as previously described ${ }^{11,12}$. End points were determined as either median egg infectious doses $\left(\mathrm{EID}_{50}\right)$ or, in the case of tissue culture, p.f.u. $\mathrm{ml}^{-1}$.

Animal studies. The ability of the parental and reassortant viruses to replicate in the upper and lower respiratory tracts of ferrets was determined as previously described ${ }^{13}$.

Genome analysis. Electrophoresis of single-stranded virion RNA was performed for both the LEN-B/14/5/1 and $A A-C R B / 117$ reassortant viruses, and their respective

Table 1 Change of phenotype of B/Leningrad/14/55 after coldadaptation

\begin{tabular}{|c|c|c|c|c|c|}
\hline \multicolumn{3}{|c|}{ No. of egg passages } & \multicolumn{3}{|c|}{$\begin{array}{c}\log _{10} \text { p.t.u. } \mathrm{ml}^{-} \\
\text {in chick kidney cells }\end{array}$} \\
\hline $32^{\circ} \mathrm{C}$ & $25^{\circ} \mathrm{C}$ & Total & $25^{\circ} \mathrm{C}$ & $32^{\circ} \mathrm{C}$ & $38^{\circ} \mathrm{C}$ \\
\hline 20 & 0 & 20 & 3.5 & 6.4 & 3.2 \\
\hline 20 & 17 & 37 & 5.9 & 6.8 & 0 \\
\hline
\end{tabular}

Table 2 Adaptation of influenza B/Ann Arbor/1/66 to growth at $25^{\circ} \mathrm{C}$ in primary chick kidney cells (PCKC) ${ }^{e}$

\begin{tabular}{lllll}
\hline & \multicolumn{2}{c}{$\begin{array}{c}\text { No. of passages } \\
\text { required for optimal } \\
\text { growth }\end{array}$} & $\begin{array}{l}\text { Maximum } \\
\text { infectious } \\
\text { titre } \\
\text { (p.f.u. ml }\end{array}$ \\
\hline $33^{\circ} \mathrm{C}$ & $30^{\circ} \mathrm{C}$ & $27^{\circ} \mathrm{C}$ & $25^{\circ} \mathrm{C}$ & $3 \times 10^{7}$ \\
\hline 2 & 2 & 1 & 1 & 3 \\
\hline
\end{tabular}

${ }^{2} \mathrm{~B} / \mathrm{Ann}$ Arbor/1/66 originally isolated in PCKC

Table 3 Comparison of ca influenza $B$ viruses for replication at differen temperatures in primary chick kidney cells (PCKC)

\begin{tabular}{|c|c|c|c|c|}
\hline & \multicolumn{4}{|c|}{ Infectivity titre (p.f.u. $\mathrm{ml}^{-1}$ ) in PCKO } \\
\hline & $25^{\circ} \mathrm{C}$ & $33^{\circ} \mathrm{C}$ & $37^{\circ} \mathrm{C}$ & $39^{\circ} \mathrm{C}$ \\
\hline \multicolumn{5}{|l|}{ Parental viruses } \\
\hline wt B/Ann Arbor/1/86 & $<10^{3}$ & $7 \times 10^{6}$ & $5 \times 10^{6}$ & $<10^{4}$ \\
\hline ca B/Leningrad/14/55 & $1 \times 10^{8}$ & $2 \times 10^{3}$ & $8 \times 10^{7}$ & $<10^{4}$ \\
\hline ca B/Ann Arbor/1/66 & $1 \times 10^{8}$ & $3 \times 10^{8}$ & $<10^{3}$ & N.D. \\
\hline \multicolumn{5}{|l|}{ Reassortant viruses } \\
\hline LEN-B/14/5/1 & $9 \times 10^{7}$ & $2 \times 10^{7}$ & $4 \times 10^{7}$ & $<10^{4}$ \\
\hline $\mathrm{AA}-\mathrm{CRB} 117$ & $2 \times 10^{\prime}$ & $5 \times 10^{7}$ & $<10^{3}$ & N.D. \\
\hline
\end{tabular}

parents, as previously described ${ }^{14.15}$. In addition, the technique of cRNA:vRNA hybridization followed by electrophoresis of nuclease S1-treated homologous and heterologous double stranded RNA's ${ }^{16,17}$ was used to confirm results with the reassortant LEN-B-14/5/1.

\section{Results}

\section{Cold-adaptation and ts phenotypes of parental viruses}

Virus B/Leningrad/14/55 was sequentially passaged 20 times in embryonated eggs at $32^{\circ} \mathrm{C}$ and then 17 times at $25^{\circ} \mathrm{C}$ to yield the modified virus designated $\mathrm{B} /$ Leningrad/ $14 / 17 / 55$. This virus could be differentiated from its progenitor in having higher levels of replication at $25^{\circ} \mathrm{C}$, and lower replication at $38^{\circ} \mathrm{C}$ in PCKC (Table 1). The virus B/Ann Arbor/1/66 was passaged at sequentially lower temperatures in PCKC until the derived ca virus replicated efficiently at $25^{\circ} \mathrm{C}$ (Table 2 ).

When the ca viruses derived in the US and USSR were compared, they were equally adapted to growth at $25^{\circ} \mathrm{C}$ (Table 3). However, in these studies, which utilized temperatures of $37^{\circ} \mathrm{C}$ and $39^{\circ} \mathrm{C}$ to detect temperature sensitivity, only the B/Ann Arbor ca virus experienced a cut-off in replication at a lower temperature than the wt B/Ann Arbor/1/86 included as a control. Thus, it appears probable that the degree of temperature sensitivity of the ca $B /$ Leningrad/14/17/55 virus is somewhat less pronounced than for the ca $B / A n n$ Arbor/1/66 virus.

\section{Cold-adaptation and ts phenotypes of reassortant viruses}

Comparison of the replication in PCKC of parental and ca reassortant viruses at different temperatures indicated that the LEN-B/14/5/1 reassortant virus was indistinguishable from its $B /$ Leningrad/14/17/55 ca parent, and the AA-CRB 117 virus was indistinguishable from its B/Ann Arbor/1/66 ca parent (Table 3). Thus, both ca reassortants replicated much better than their contemporary wt parent $\mathrm{B} / \mathrm{Ann}$ Arbor $/ 1 / 86$ at $25^{\circ} \mathrm{C}$, whereas only the AA-CRB117 virus, but not the LEN-B/14/5/1 virus, was restricted in replication at $37^{\circ} \mathrm{C}$. 
Table 4 Replication of ca B/Leningrad/14/55 virus and its c.a. reassortant $L E N-B / 14 / 5 / 1$ in embryonated eggs at different temperatures

\begin{tabular}{lllll}
\hline & \multicolumn{4}{c}{ Titre $\left(\log _{10}\right.$, EID } \\
\cline { 2 - 5 } Virus & $25^{\circ} \mathrm{C}$ & $34^{\circ} \mathrm{C}$ & $37^{\circ} \mathrm{C}$ & $38^{\circ} \mathrm{C}$ \\
\hline wt B/Ann Arbor/1/86 & 2.25 & 7.25 & 6.25 & 1.25 \\
ca B/Leningrad/14/17/55 & 6.0 & 7.5 & 7.0 & 1.0 \\
ca LEN-B/14/5/1 & 6.5 & 8.5 & 7.75 & 2.5 \\
\hline
\end{tabular}

Titration of the Leningrad viruses in embryonated eggs confirmed the cold-adaptation phenotype of the parental and reassortant ca viruses (Table 4). In this host system, as in PCKC, temperature sensitivity was not detected at $37^{\circ} \mathrm{C}$ for the ca Leningrad parent or reassortant. Because even wt influenza $B$ virus does not replicate reliably in eggs at $38^{\circ} \mathrm{C}$ no meaningful evidence of ts phenotype could be obtained from the ca $B /$ Leningrad viruses in eggs. Egg infectivity titrations at different temperatures were not carried out for the B/Ann Arbor/1/66 ca virus, or its ca reassortant. Clone LEN-B/14/5/1 was passed in eggs at $34^{\circ} \mathrm{C}$ five times to determine the possible alteration in ca phenotype. Titration in eggs after the fifth passage showed no changes (not shown).

\section{Replication in ferrets}

In two experiments a total of four ferrets each were infected in parallel with wt virus B/Ann Arbor $/ 1 / 86$, ca parental viruses $B /$ Leningrad/14/17/55 and $B / A n n$ Arbor/1/66, and the ca reassortant viruses LEN-B/14/5/1 and AA-CRB117. The wt contemporary virus B/Ann Arbor/1/86 was detected in both trachea and lungs at 3 days postinfection, with lung titres being about 2 logs less than in the trachea (Table 5).

Infection was associated with fever lasting 2 days in all animals. The cold-adapted B/Leningrad/14/17/55 virus replicated in lungs to a titre about 2 logs lower than in the trachea. Only two of four ferrets experienced fever, of one day duration in both cases.

Reassortant ca virus LEN-B/14/5/1 differed from both parent viruses in replicating only in trachea, not lungs. Two of four ferrets experienced low level fever of $39.9^{\circ} \mathrm{C}$, a borderline increase compared with the normal baseline of $39.7^{\circ} \mathrm{C}$ for ferrets. Thus the reassortant LEN-B14/5/1 appeared to be closer to having full attenuation than its ca parent, although evidence of marginal pathogenicity was evident in this animal model.

Neither the ca B/Ann Arbor/1/66 parent virus, nor its reassortant AA-CRB117, replicated to detectable levels in ferret lungs, despite quite high levels of replication in trachea. Likewise, neither of these two viruses elicited evidence of febrile reaction, or coryza. Thus, both were highly attenuated.

\section{Discussion}

Live influenza $B$ vaccines were used in the USSR for many years, and cold-adapted influenza $B$ vaccine was developed by $1965^{10,11}$. However, relatively little information exists about such vaccines, and most vaccine development and research has focused on influenza $A$.
Although one reason for this may be the perception that influenza $B$ poses a lower risk than influenza $A$, beginning in 1979 influenza $B$ has been responsible for quite major epidemics, involving high risk adults, as well as children. Excess mortality has been consistently evident $^{18,19}$. In addition, the use of inactivated influenza $B$ vaccine may on many occasions provide inadequate protection, particularly in the elderly ${ }^{20,21}$. This may be due to low immunogenicity of influenza $B$ vaccine ${ }^{21.22}$ or the failure to include the optimum virus strain in the vaccine on account of virus genetic and antigenic heterogeneity, and the rapid spread of new variants ${ }^{23}$.

The availability of live attenuated influenza $B$ vaccine might contribute to improved ability to control this disease, at least in some segments of the population. This would particularly be so, were such a vaccine to offer broader or more long-lasting immunity than inactivated vaccine, as has been hoped for in the case of type A virus.

This report indicates that in theory it is possible to prepare new vaccinal strains containing contemporary surface antigens, by reassortment with ca parental virus. The biological marker of cold-adaptation was reproducibly transferred to reassortants, as was the ts phenotype if the appropriate host system was used for its detection. Ferret virulence was also reproducibly transferred in the case of the B/Ann Arbor/1/66 virus, but for the B/Leningrad/14/55 virus the modest residual virulence in the ca parent was reduced slightly further in its reassortant.

Based on the in vitro and animal model data, it might be expected that the B/Ann Arbor/1/66 ca virus would prove more acceptable as a donor strain for making live vaccines, in view of its slightly higher temperature sensitivity, and lower levels of replication in ferret lungs than the $B /$ Leningrad/14/55 virus.

Unfortunately, it is still not possible to extrapolate directly from in vitro or animal studies to human clinical experience. For example the reassortant vaccine LEN-B/14/5/1 was in fact highly attenuated ${ }^{9}$. Clinical studies are being undertaken in the US with the B/Ann Arbor reassortant virus.

Considerably more laboratory and clinical experience is needed before it will be known how reproducibly live attenuated influenza vaccines can be prepared, and their general efficacy determined. The only reported field study of efficacy in a natural challenge indicated some beneficial effect from a ca vaccine, but the virus was of a different origin from that studied here ${ }^{24}$. Small scale volunteer studies with a ca reassortant of B/Ann Arbor/1/66 did demonstrate safety and immunogenicity, as well as efficacy against artificial challenge with a wt strain ${ }^{25.26}$. It will also be necessary to evaluate the ability to combine influenza B with one or more type A components without interference occurring, or dilution of the type $B$ virus below its infectious threshold in man. Finally, genetic stability must be established. The availability now of data on the genome sequence of at least the B/Ann Arbor/1/66 vaccine candidate, and preliminary data on gene constellations associated with attenuation, will assist this process $^{27,28}$.

In conclusion, the data obtained support from the theoretical concept that live attenuated influenza $B$ vaccines can be readily obtained by reassortment with cold-adapted parents, including the transfer of defined laboratory markers. Such vaccines warrant further evaluation of their practical application in man. 


\section{Acknowledgements}

Work by Dr H.F. Maassab was supported by the National Institute of Allergy and Infectious Disease, Development and Application Research, NIH Contract 1-A1-52564. These studies were conducted under the auspices of the Joint Health Sciences agreement between the US and USSR in the area of Influenza and Hepatitis.

\section{References}

1 Maassab, H.F., Kendal, A.P. and Davenport, F.M. Hybrid formation of influenza virus at $25^{\circ} \mathrm{C}$. Proc. Soc. Exp. Biol. Med. 1972, 139, 768

2 Kendal, A.P., Maassab, H.F., Alexandrova, G.I. and Ghendon, Y.Z. Development of cold-adapted recombinant live attenuated influenza A vaccines in the USA and USSR. Antiviral Res. 1981, 1, 339

3 Wright, P.F. and Karzon, D.T. Live attenuated influenza vaccines. Prog. Med. Virol. 1987, 34, 70

4 Alexandrova, G.I. Basic trends in vaccination of children against influenza by use of live vaccine. Proc. Symp. on Live Influenza Vaccine, Yugoslav Academy of Sciences and Arts, Zagreb, 1971, p. 121

5 Maassab, H.F., DeBorde, D.C., Donabedian, A.M. and Smitka, C.W. Prospects for Influenza type B live attenuated vaccines. In: Options for the Control of Influenza (Eds Kendal, A.P. and Patriarca, P.A.) Alan R. Liss, NY, 1986, p. 271

6 World Health Organization. Influenza in the world. October 1985-September 1986. WHO Wkly Epidem. Rec. 1987, 5, 21

7 CDC. Influenza-United States, 1985-1986 season. Morbid. Mortal. Wkly. Rep. 1986, 75, 470

8 World Health Organization. Recommended composition of influenza virus vaccines for use in the 1986-1987 season. WHO Wkly Epidem. Rec. 1986, 9,61

9 Obrosova-Serova, N.P., Slepushkin, A.N., Kendal. A.P., Harmon, M.W., Burtseva, E.I., Bebesheva, N.I. et al. Evaluation in children of cold adapted influenza $B$ live attenuated intranasal vaccine prepared by reassortment between wildtype B/Ann Abor/1/86 and cold-adapted $B /$ Leningrad/14/55 viruses. Vaccine $1990,8,57-60$

10 Alexandrova, G.I. and Smorodintsev, A.A. Obtaining of an additionally attenuated vaccinating cryophyl influenza strain. Rev. Roum. D'inframicrobiol. 1965, 2, 179

11 Maassab, H.F., Francis, T., Davenport, F.M., Hennesey, V., Minuse, E. and Anderson, G. Laboratory and clinical characteristics of attenuated strains of influenza virus. Bull. WHO 1969, 41, 589

12 Garmashova, L.M., Polezhaev, F.I. and Alexandrova, G.I. Coldadapted A/Leningrad/134/47/57 (H2N2) strain, a special donor of attenuation of live influenza vaccine for children, and recombinants produced on its base. Vopr. Virusol. 1984, 1, 28

13 Maassab, H.F., Kendal, A.P., Abrams, G.D. and Monto, A.S. Evaluation of a cold-recombinant influenza virus vaccine in ferrets. J. Infect. Dis. 1982, 146,780

14 Cox, N.J., Maassab, H.F. and Kendal, A.P. Comparative studies of wild-type and cold-mutant (temperature-sensitive) influenza viruses: a non-random reassortment of genes during preparation of live virus vaccine candidates by recombination at $25^{\circ} \mathrm{C}$ between recent H3N2 and HINt epidemics strains and cold-adapted A/Ann Arbor/6/60. Virology 1979, 97, 190

15 Donabedian, A.M. DeBorde, D.C. and Maassab, H.G. Genetics of cold-adapted B/Ann/Arbor/1/66 influenza virus reassortants. The acidic polymerase (PA) protein gene confers temperature sensitivity and attenuated virulence. Microbiol. Pathol. 1987, 3, 97

16 Hay, A.J., Bellamy, A.R., Abraham, G., Skehel, J.J., Brand, C.M and Webster, R.C. Procedures for characterization of the genetic material of candidate vaccine strains. Develop. Biol. Stand. 1977, 29, 15

17 Ghendon, Y.Z., Klimov, A.I., Alexandrova, G.I. and Polezhaev, F.I Analysis of genome composition and reactogenicity of recombinants of cold-adapted and virulent virus strains. J. Gen. Virol. 1981, 53, 215

18 Nolan, T.F., Goodman, R.A., Hinman, A.R., Noble, G.R., Kendal, A.P. and Thacker, S.B. Morbidity and mortality associated with the influenza B in the United States, 1979-1980. A report from the Center for Disease Control. J. Infect. Dis. 1980, 142, 360

19 Lui, K.J. and Kendal, A.P. Impact of influenza epidemics on mortality in the United States from October 1972 to May 1985. Am. J. Publ Hith. 1987, 77, 712

20 Hail, W.N., Goodman, R.A., Noble, G.R., Kendal, A.P. and Steece R.C. An outbreak of influenza $B$ in an elderly population. J. Infect Dis. 1981, 144, 297

21 Arden, N.H., Patriarca, P.A. and Kendal, A.P. Experiences in the use and efficacy of inactivated influenza vaccine in nursing homes. In: Options for the Control of Influenza (Eds Kendal, A.P. and Patriarca, P.A.) Alan R. Liss, NY, 1986, p. 155

22 Arden. N.H., Patriarca, P.A., Lui, K.J., Harmon, M.W., Brandon, F. and Kendal, A.P. Safety and immunogenicity of a $45 \mu \mathrm{g}$ supplemental dose of inactivated split-virus influenza $B$ vaccine in the elderly. $J$. Infect. Dis. 1986, 153, 805

23 Centers for Disease Control. Update: Influenza activity-United States-and influenza type B virus drift. Morbid. Mortal. Week. Rep. 1986, 35, 92

24 Monto, A.S., Miller, F.D. and Maassab, H.F. Evaluation of an attenuated, cold-recombinant influenza B virus vaccine. J. Infect. Dis. 1982, 145, 57

25 Davenport, F.M., Hennessy, A.V., Maassab, H.F., Minuse, E., Clark L.C., Abrams, G.D. and Mitchell, J.R. Pilot studies on recombinan cold-adapted live type $A$ and $B$ influenza virus vaccines. J. Infect. Dis. 1977, 136, 17

26 Keitel, W.A., Cate, T.R. and Couch, R.B. Evaluation of a coldrecombinant influenza $B$ vaccine. In: Options for the Control of Influenza (Eds Kendal, A.P. and Patriarca, P.A.) Alan R. Liss, NY, 1986, p. 287

27 DeBorde, D.C., Donabedian, M., Herlocher, L., Naeve, C.W. and Maassab, H.F. Sequence comparison of wild-type and cold-adapted B/Ann Arbor/1/66 influenza virus genes. Virology 1988, 163, 429

28 Donabedian, A.M., DeBorde, D.C., Cook, S., Smitka, C.W. and Maassab, H.F. A mutation in the PA protein gene of cold-adapted $B / A n n$ Arbor/1/66 influenza virus associated with reversion of temperature sensitivity and attenuation. Virology 1988, 163, 444 